\title{
Design of near optimal user interface with minimal Ul elements using evidence based recommendations and multi criteria decision making: TOPSIS method
}

\author{
Subbiah Vairamuthu* and \\ S. Margret Anouncia
}

School of Computer Science and Engineering,

VIT University,

Vellore-632014, Tamilnadu, India

Email: svairamuthu@vit.ac.in

Email: anouncia@gmail.com

*Corresponding author

\begin{abstract}
One among the research challenges in human computer interaction (HCI) is to build user interfaces in the way that make users satisfy. This would improve the usability of an information system. In general, usability is one of the non-functional requirements which decides the acceptability. Usability factors when not considered properly during interaction design will lead spending more cost and time for any organisation. Simple interaction styles with guiding user interface components for navigations will improve the users' interaction. The improved interaction thus would facilitate in improving the users satisfaction towards using any information system. In this work, it has been attempted to recommend designers to build user interface with minimal components without compensating the effectiveness. For this process, the multi criteria decision making (MCDM) approach technique for order preference by similarity to ideal solution (TOPSIS) was employed in this work.
\end{abstract}

Keywords: human computer interaction; HCI; user interface; TOPSIS; multi criteria decision making; MCDM; interaction styles; positive ideal solution; PIS; negative ideal solution; NIS.

Reference to this paper should be made as follows: Vairamuthu, S. and Anouncia, S.M. (2018) 'Design of near optimal user interface with minimal UI elements using evidence based recommendations and multi criteria decision making: TOPSIS method', Int. J. Humanitarian Technology, Vol. 1, No. 1, pp.40-65.

Biographical notes: Subbiah Vairamuthu holds a $\mathrm{PhD}$ in Computer Science and Engineering associated with VIT University for the past ten years. He has very good record of academics. He had authored and co-authored several articles in journal of repute at international levels. His research interests include software engineering, usability of information systems, human computer interaction, soft computing techniques and computer networks. He is more fascinated with programming and user interface design.

S. Margret Anouncia is currently a Professor in School of Computer Science and Engineering. She has around 25 years of experience. Her previous designations include Former Dean of the school where she is presently serving. She has produced six $\mathrm{PhD}$ graduates. She loves to teach software engineering. Her research domains include image processing, human computer interaction, information retrieval. Her reputed contributions in the form of research articles can be found in several international journals. 


\section{Introduction}

The growing capability and ubiquity of IT has traditionally influenced the way people work, the way they maintain relationships, and the way an individual manage their everyday lives. The role of information technology envisaged the future with an intensive effort for achieving world widespread digital participation and contributions. Effective digital participation can be improved through improving the usability. One factor that influences the usability is the user interface (UI). Creation of UIs for information systems is a challenging and continuing research feature in human computer interaction (HCI) field since those interfaces convey meaningful information using different modalities. Technological advances revolutionised the mode of interaction with information systems. In addition, these advances also made people understand that the HCI philosophy has drastically improved over the recent years. Researchers in many aspects of HCI had extended those understanding of what it meant to interact with information technology and to apply those understanding during their information systems design. Hence, HCI is considered to have more orientation towards open problems that are to be addressed in near future.

In existing HCI scenario, decision makers rely upon various criteria based on many dissimilar requirements of UI that are extracted from the application requirement. To arrive at a decision, several approaches are being used. One of the existing methods that provide substantial research scope is multi criteria decision making (MCDM) methods had been widely generalised so that it could process any kind of information viz., interval valued, Fuzzy values or any flavours in fuzzy methods. The method technique for order preference by similarity to ideal solution (TOPSIS) based on MCDM analysis provide freedom to decision makers to model their opinions thereby providing individuality to decision makers. The work proposed here emphasises on recommendations for designing near optimal UI with minimal set of UI elements wherever possible with their alternatives. The decision to arrive at this stated objective uses TOPSIS MCDM method.

\section{Literature review}

One of the major elements of software applications considered to be critical is UI as they mentally model user's functionality. A number of well contrived and robust applications had eventually failed as they failed to adopt effective UI design. A few development techniques associated with UI design viz., universal design (Mace et al., 1990), design for all (Stephanidis, 1997) and inclusive design (Keates et al., 2000) encouraged the idea of creating one UI design to fit as many users as possible. However, no UI is autonomous from their context-of-use that may be determined in terms of a platform, a user and environment (Calvary et al., 2003). It was not possible for 'one design for all' method to accommodate all variable cases in context-of-use and it lead to reducing the satisfaction of users' experience. Designing more than one UI for similar or same functionally equivalent tasks due to varying context would be a difficult task as the scope of varying context could not be known completely during design time and also there was huge amount involved in developing many versions of UI manually. For this reason, adaptive UIs started to get into real focus and been promoted as one of the alternatives for varying context-of-use. Multi-target or multi-context UIs started blooming with a capability of 
adapting to their dynamic context-of-use. An important goal behind those adaptive UIs was plasticity that represents the ability of UI to preserve the system's usability across dynamic context-of-use (Coutaz, 2010).

Nielsen in 1986 introduced in his article a virtual protocol for analysing the interactions between computers and human that contains seven levels. The levels were decomposed using linguistic criteria viz., alphabetical, goal, lexical, pragmatic, physical, semantic and syntactical. This idea was initially considered as useful but the same was not implemented as a model anywhere. This linguistic classification attracted many researchers to classify modifications in UIs as part of improving process (Pederiva et al., 2007) or for classifying the usability guidelines (Vanderdonckt, 1997). Though variety of UI models exists, every model has their own specific point of view to their domains that guide the abstraction of the modeller and control the modelling choices and decisions. The Cameleon reference framework (CRF) (Shen and Pantic, 2013) identified various levels of abstraction for any UI as follows: task model, abstract user interface (AUI) model, concrete user interface model (CUI) and final user interface model (FUI). These models determine modalities and platform dependencies that influence designer's decision.

Enormous applications suffered from usability issues and problems since their UIs did not catered their context dynamism. Topi et al. (2005) studied such systems related to enterprise resource planning. Singh and Wesson in 2009 suggested that adaptive UIs had been recommended for improving usability in software applications by outfitting to the dynamic user needs. Several methods and techniques were initiated for promoting adaptive UI design so as to target various kinds of software systems built on aspects based on accessibility (Gajos et al., 2010), concurrency-based tasks (Bihler and Mügge, 2007), natural context (Blumendorf et al., 2007), culture (Reinecke and Bernstein, 2011) and platform (Demeure et al., 2008). Contributions from Byrne and Parasuraman (1996) and Solovey et al. (2011) elucidated non-technical aspects and concluded about the diversity of research scope in UI design.

Studies have shown that opportunity to better understand and comprehend the preliminary experiences of technology by older people and adopt them will be more challenging (Lindsay et al., 2012). Recently, professional practices reflected that the development of service design in UIs had alarmed gaining background understanding of any kinds of users with modern technologies (Sangiorgi and Prendiville, 2014). Research in $\mathrm{HCI}$ domain had been evaluated and criticised by many scholars as it focused much narrowly to understand the barriers and difficulties experienced by all categories of users specifically older people concerning technology transitions that added a view over AFs (Rogers et al., 2014; Sun et al., 2014).

Usable UI development still remains a complex and challenging activity for any information systems. The major reasons for this complexity arise out of heterogeneity of users and data along with the perspectives. People with different objectives and abilities use different devices to interact with the machine virtually in different environments. Providing users with proper and perfect UI is realistically hard to achieve. To accommodate with existing changes continuously in IT era, designers must be prepared to meet those situations. As $\mathrm{W} 3 \mathrm{C}$ has recommended model-based user interface approaches (MB-UI), it received attention a lot because of their advantages and benefits (Calvary and Coutaz, 2014). Ultimately, the aims of those approaches were to report the complexity in interaction and UIs. Those complexities were addressed mainly by using: 
1 abstraction: isolation of problem and focus on most important aspect

2 enforcement of engineering disciplines establishing systematic ways for developing systems.

To enable implement a change in UI model, one must need to identify the place to carry out the specified change, determine the elements that would be affected by those changes along with their implications. The quality attributes related to the implications by changes as mentioned are maintainability and traceability.

UI designers rely upon many criteria during their developments. The methods to sustenance decisions by an individual decision maker are extensively being investigated. One among the most accepted and successful method is the TOPSIS. Yoon and Hwang (1995) formulated the method in 1981 get major attention now-a-days among researchers. It is simple and very intuitive method. Main idea behind TOPSIS is that the positive ideal solution (PIS) must be too far from the negative ideal solutions (NIS) and also closer to the best possible solution. The standard TOPSIS method permits only single decision maker to contribute towards the best solution which can be considered as one of the disadvantages. Many times decisions are truly made by a decision maker in real times. To overcome this limitations, several scholars identified various generalisation strategies to make TOPSIS applicable for group decision making (DM) as stated by Boran et al. (2009), Chen and Shih (2012), Krohling and Campanharo (2011), Shih et al. (2007) and Vahdani et al. (2011).

A dominant limitation of standard TOPSIS was that it dealt with only crisp values. Unsurprisingly, many scholar generalised the TOPSIS to make it deal with interval numbers (Dymova et al., 2013; Jahanshahloo et al., 2009; Yue, 2011), fuzzy data (Chen, 2000; Krohling and Campanharo, 2011; Lee et al., 2014) intuitionistic fuzzy information (Boran et al., 2009), probability distribution values (Lourenzutti and Krohling, 2014; Xiong and Qi, 2010) and hesitant fuzzy inputs (Xu and Zhang, 2013). Though various generalisations were proposed, methods to deal with heterogeneous information in TOPSIS were limited. A modified TOPSIS method proposed in Peng et al. (2012) supported decision makers by handling values with different granularity by converting the heterogeneous values to a unique data so that TOPSIS could be applied. The phenomena that all the decision makers using TOPSIS was that the DM process employs various criteria in a static environment. The TOPSIS idea was protracted by Wang and Wang (Run-qi et al., 2008) so as to make it deal with heterogeneous values in a single context.

Fuzzy linear programming technique for multidimensional analysis of preference (LINMAP) developed by Wan and $\mathrm{Li}$ (2013) was employed to conclude any heterogeneous values. In the work (Espinilla et al., 2013), the authors formulated an approach for solving heterogeneous MCDM problems. Though there were variations in TOPSIS for minimising shortcomings (Run-qi et al., 2008), it was able to process Gaussian distribution and random variables by minimal transformation of known inputs since the random variables may be used to model fuzzy values in many circumstances. The difficulty of decision makers and the DM processes need not be restricted with varied types of information. In many cases, the preference rank of chosen alternatives may purely rely and depend on some factors like time which could not be controlled which might be more common. Reasonable research contributions were made to consider heterogeneous data and relations in varying environment as stated in Pérez et al. (2011, 
2010). Techniques which use preference relations had a different approach when compared them with ratings based techniques such as TOPSIS as studied in the work (Ureña et al., 2015).

\section{Interaction and UI design: overview}

Designing interactions involve creating interfaces during complex situations with the help of technologies of various types including computer software, physical devices and the web. Design involves various criteria such as achieving the stated goals, specified constraints, understands machine and humans involved in interaction. The iterative process of design has several stages which could not be stated as complete always. Interactions usually start with recognising the users and identifying their environment. Scenarios may be used throughout the design process to seek user's requirements. Also, they may elucidate sequential walkthrough of users' interaction. Interaction design is illustrated in Figure 1.

Figure 1 The interaction design process

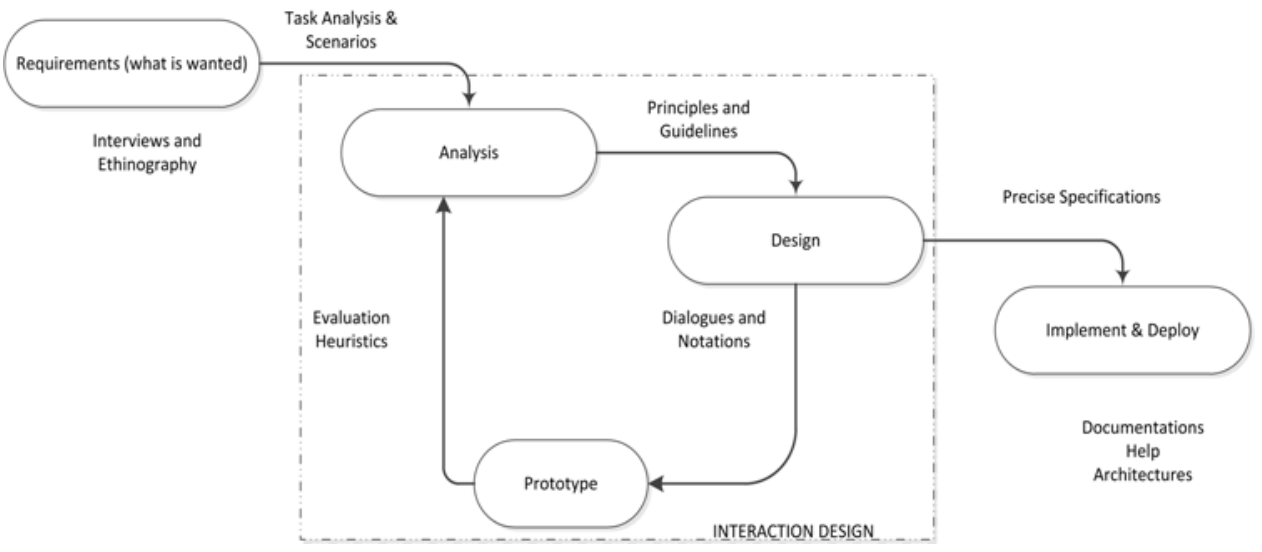

Interaction design can be viewed as the structure and behaviour of an interactive system. It can also be viewed as the relationship between the product and any user together with the services they use. It is expected that interaction design must create greater experience with any users. This requires understanding of basic principles involved underlying the UI design. There are five major principles of interaction design that must be considered which are:

1 match user's expectations and experience

2 consistency in UI design

3 functional minimalism

4 reduce cognitive loads

5 meaningful engagement of users. 
Playing a vital role in core design, this interaction design tends to use existing principles and guidelines during UI design. Proper use of heuristics to evaluate the prototypes also contributes towards acceptability.

Though interaction design is interdisciplinary in nature, the following definition from Oxford English dictionary captures the core of design: "(design is) a plan or scheme conceived in the mind and intended for subsequent execution". Hence, design involve scheme or plan development. During interaction design, one has to examine the artefact's use and end user's domain by considering a user-centred approach. Though chances for a design may be used by one individual, it should be unlikely that only the concerned person would be involved in designing and using any system and hence the plan should be communicated.

Four basic activities were involved in interaction design as given below:

1 requirements [identify the needs] and establish the requirements

2 develop alternate designs

3 build interactive versions

4 evaluate and accept.

The three major characteristics of the interaction design process include users focus, usability criteria and iterations. As a designer progress towards constructing UIs, they should consider how the above mentioned characteristics could be pulled together as a coherent process. In order to achieve this in practice, one has to clear with vague ideas related to know about their users and their actual needs together with the methods to produce alternative design solutions and the way to choose the optimal one.

\section{Insight into MCDM and TOPSIS}

The MCDM approach can be considered as one of the complex tool for DM which involves qualitative and quantitative factors. Recently, various MCDM approaches and techniques were introduced to choose the probable optimal solution. This method had grown as part of operations research (OR), connected to design of mathematical and computational tool to support the evaluation of performance criteria in DM process by the decision makers subjectively. Many researchers proposed various studies to introduce changes in MCDM so that the method can be employed in their related domain including materials, supply chain management, knowledge management, information management, quality management, etc. Since its inception, MCDM was considered to be one of the active research areas and ended up with a number of theoretic and applied approaches and books. MCDM technique had been devices to elect a preferred alternative or classify the alternatives from a number of choices or to rank them based on a subjective preference. The method was considered to be a general method to help users facilitating DM from more than one available preference where the chances of conflicts were high. MCDM approach was considered to be dealing with composite and complex problems by dividing the problems into tiny pieces initially.

Many innovations were proposed to existing MCDM previously, the following methods were considered to be important among them: 


\author{
a AHP \\ b ELECTRE \\ c fuzzy AHP \\ d fuzzy TOPSIS \\ e PROMETHEE \\ f TOPSIS \\ g VIKOR.
}

TOPSIS is considered to be a useful tool to deal with MCDM problems in real world. It facilitates decision makers organising problem to be solved along with their own analysis so as to make comparisons with alternatives so as to rank them. It was accepted almost by all the researchers for solving the above mentioned categories of problem. The fundamental idea of TOPSIS is quite simple and straight forward. It instigates form the notion of expatriate ideal point from where the solution of compromise has the nearest distance. In other words, TOPSIS tries to find the closest solution as possible to the optimal solution. Also, TOPSIS have the ability to find the best among the alternatives in easier way. TOPSIS to rank alternatives using distance was proposed that finds its acceptance among all the researchers even today (Yoon and Hwang, 1995). The chosen alternative should be the shortest one from the PIS and the same must be farthest distant from the negative ideal solution (NIS) so as to choose the best alternative. This method considers the distance to both positive and negative ideals and order of preference is also ranked accordingly relative to their distance closeness. The PIS aims for maximising the benefits and minimising the cost while NIS aims for the other case.

Contributions made by several scholars claimed that TOPSIS was considered to be more advantageous due to the following reasons:

- it accounts for both PIS and NIS simultaneously to rank alternatives

- logic sounds good which characterises human choice

- alternatives and their performance can also be viewed

- computation is simple.

These advantages made TOPSIS a critical method when compared with other MCDM methods. Many variations of TOPSIS in literature of MCDM were proposed and some of them were successful including adjusted TOPSIS (A-TOPSIS), conventional TOPSIS (C-TOPSIS) and modified TOPSIS (M-TOPSIS).

\title{
4.1 Steps in MCDM problem solving approach
}

MCDM uses the following procedures:

- establish the decision context, the decision objectives (goals), and identify the decision maker(s)

- identify the alternatives

- identify the criteria (attributes) that are relevant to the decision problem 
- for each of the criteria, assign scores to measure the performance of the alternatives against each of these and construct an evaluation matrix (often called an options matrix or a decision table)

- standardise the raw scores to generate a priority scores matrix or decision table

- determine a weight for each criterion to reflect how important it is to the overall decision

- use aggregation functions (also called decision rules) to compute an overall assessment measure for each decision alternative by combining the weights and priority scores

- perform a sensitivity analysis to assess the robustness of the preference ranking to changes in the criteria scores and/or the assigned weights.

\subsection{TOPSIS problem solving approach}

In this method, two artificial alternatives are hypothesised: ideal alternative: the one which has the best level for all attributes considered. Negative ideal alternative: the one which has the worst attribute values. TOPSIS selects the alternative that is the closest to the ideal solution and farthest from negative ideal alternative. TOPSIS assumes that we have $m$ alternatives (options) and $n$ attributes/criteria and we have the score of each option with respect to each criterion.

Let $x \_i j$ score of option $i$ with respect to criterion $j$.

We have a $m \times n$ matrix $\boldsymbol{X}=\left(x_{i j}\right)$.

Let $J$ be the set of benefit attributes or criteria (more is better).

Let $J^{\prime}$ be the set of negative attributes or criteria (less is better).

Step 1 Construct normalised decision matrix. This step transforms various attribute dimensions into non-dimensional attributes, which allows comparisons across criteria. Normalise scores or data as follows:

$$
r_{i j}=\frac{x_{i j}}{\sqrt{\sum x_{i j}^{2}}} \text { for } i=1,2, \ldots, m ; j=1,2, \ldots, n
$$

Step 2 Construct the weighted normalised decision matrix. Assume we have a set of weights for each criteria $w_{i}$ for $j=1,2, \ldots, n$. Multiply each column of the normalised decision matrix by its associated weight. An element of the new matrix is:

$$
v_{i j}=w_{i} r_{i j}
$$

Step 3 Determine the ideal NIS and PIS.

$$
A^{*}=\left(v_{1}^{*}, v_{2}^{*}, \ldots, V_{n}^{*}\right)
$$

where

$$
v_{j}^{*}=\left\{\begin{array}{cc}
\max \left(v_{i j}\right) \text { if } j \in J ; & \min \left(v_{i j}\right) \text { if } j \in J^{\prime} \\
i & i
\end{array}\right\}
$$


NIS

$$
A^{\prime}=\left\{v_{1}^{\prime}, v_{2}^{\prime}, \ldots, v_{n}^{\prime}\right\}
$$

where

$$
v^{\prime}=\left\{\begin{array}{cc}
\max \left(v_{i j}\right) \text { if } j \in J ; & \min \left(v_{i j}\right) \text { if } j \in J^{\prime} \\
i & i
\end{array}\right\}
$$

Step 4 Calculate the separation measures for each alternative. The separation from the ideal alternative is:

$S_{i}^{*}=\left[\sum_{j}\left(v_{j}^{*}-v_{i j}\right)^{2}\right]^{\frac{1}{2}} i=1,2, \ldots, m$

Similarly, the separation from the negative ideal alternative is:

$$
S_{i}^{\prime}=\left[\sum_{j}\left(v_{j}^{*}-v_{i j}\right)^{2}\right]^{\frac{1}{2}} i=1,2, \ldots, m
$$

Step 5 Calculate the relative closeness to the ideal solution $C_{i}^{*}$.

$$
C_{i}^{*}=\frac{S_{i}^{\prime}}{\left(S_{i}^{*}+S_{i}^{\prime}\right)}, 0<C_{i}^{*}<1
$$

Select the alternative with $C_{i}^{*}$ closest to 1 .

Thus, TOPSIS a MCDM approach can be used to choose the best among the alternative solutions.

\section{TOPSIS in GUI design process}

The main objective of this work is to identify the minimum number of UI controls or elements in UI of an application so as to minimise the number of keystrokes for simplified interactions. The implicit requirement of this core objective is to identify the suitable interaction style for any category of users. By identifying the suitable interaction style for varied classes of users will help to design a better UI. The suitable set of UI components for different interaction styles was already recommended. For example, consider the user who is 30 years old but has no knowledge in computers and have moderate experience in interactions. In this approach, it will identify the suitable interaction style for this age category. Then, based on the recommendations from $\mathrm{W} 3 \mathrm{C}$ and several research contributions, the identified UI controls would be mapped for the identified interaction style. The same process is illustrated diagrammatically as follow in Figure 2: 
Figure 2 TOPSIS in UI design process flow

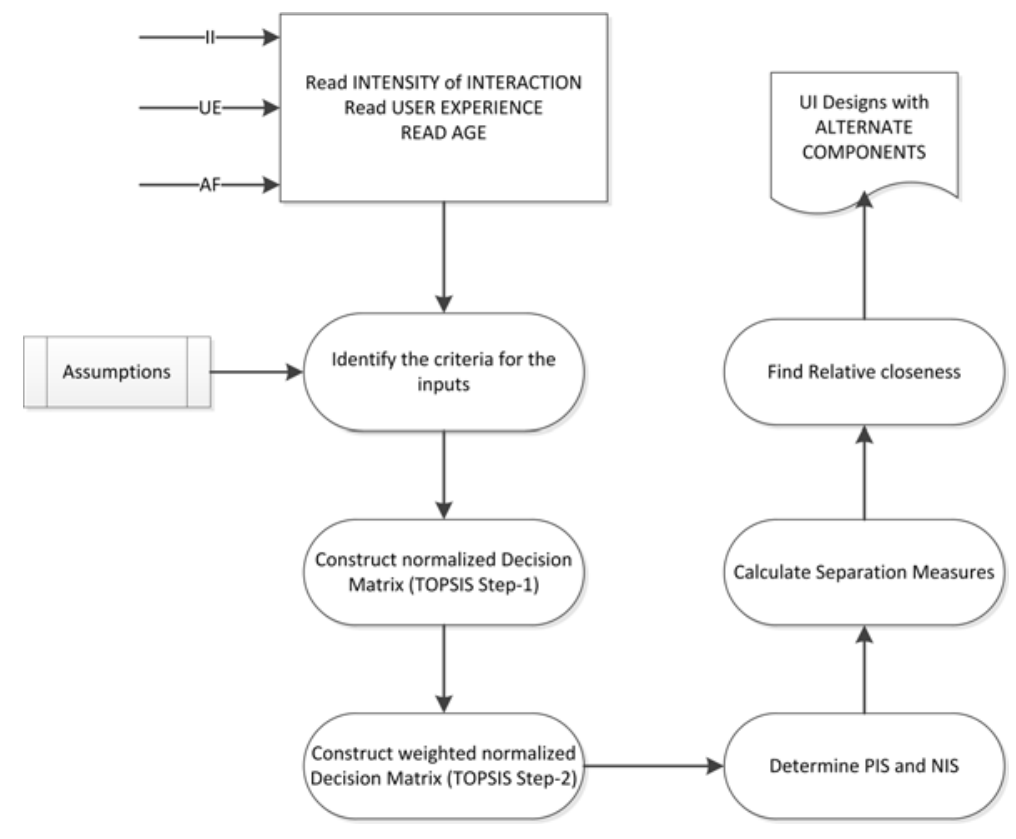

Investigating the existing information systems and from the contribution from different sources, it was found that the influencing criteria which decide the usability of any information systems include intensity of interaction (II), user's experience (UE) and age factor (AF).

As given in Figure 2, the system needs three basic inputs for the process of DM while designing UI as stated. Inputs based on the end UE will then be associated with the suitable interaction styles for them which then would ideally mapped with the design components.

\subsection{Mapping inputs to the system}

This section elaborates the idea of choosing the best among the design alternative with the chosen user criteria. Few assumptions were to model this system based on previous evidences in the literature for this method. This system for recommendation requires three parameters viz. II, UE, AF as identified above. The designer basically feed the values for the chosen parameters into the recommender system. The following shows the fuzzy mapping of input criteria. Basically, interaction in any information system would be decided by the combination of multiple factors viz. key strokes, mouse clicks, navigation, etc., In this work, it is decided to consider the following factors for II. In a traditional interaction, keystrokes and mouse clicks dominate in all the levels though there are other factors like navigation, icons and windows. So, those two factors are considered for modelling IIs. II basically includes the following other factors: the following shows modelling of II: 
a number of mouse clicks

b number of key strokes

c number of navigations

d number of windows

e number of icons/images.

As mentioned, the first two criteria dominate in all the levels of interaction and hence their contributions in interaction design alone will be considered for this recommendation method.

$$
\text { Intensity of interaction (II) }=\frac{(A+B)}{(A+B+C+D+E)} \times 100
$$

Normally in any interaction system, the intensity of user interaction falls into any one of the three categories: low, medium and high based on the number of key strokes and mouse clicks ignoring the other abovementioned factors.

Based on the calculated value using above equation (1), the criteria would be given the following fuzzy values:

$$
\text { Intensity of interaction (II) }=\left\{\begin{array}{cc}
\text { Low, } & \text { if } 0<I I<30 \\
\text { Medium, } & 31<I I<60 \\
\text { High, } & 61<I I<100
\end{array}\right\}
$$

UE, the second input criteria can be modelled using with the factors years of familiarity with computers and adequacy of input devices for interaction. Owing to the technological advancement and varying classes of users, they are classified into five different categories namely:

- novice (one who do not know anything about computers)

- manageable (one who can manage themselves with devices or systems)

- adequate (one who is capable of learning for the need)

- skilled (users with computing knowledge)

- expert (one who is able to use any kinds of system or devices).

Based on the existing scenario, it was found that the end users familiarity with the system influence this factor than the input device adequacy. As stated, users may adapt to the advancement in technological changes, it is evident that one out of the two chosen factors would contribute more likely towards this criteria. So, the two factors years of experience (YE) and the adequacy of devices (IDA) would proportionately contribute $80 \%$ and $20 \%$ respectively towards this criteria. To draw conclusions on the chosen factors for the criteria UE, the following fuzzy mappings has been employed:

YE for the end users takes the value between 1 and 5 for the mentioned categories of users (novice -1 , manageable -2 , adequate -3 , expert -4 and skilled -5 ) based on their familiarity with the computers in terms of number of years in the fuzzy range classified 
as $1-5,6-10,10-15,15-20$ and above 20 respectively for the varied categories of users. Also, the adequacy of users with computing devices takes the ordinal value in the range 1-5 1 being the lowest.

Table 1 Mapping of fuzzy values into ordinal numbers

\begin{tabular}{lcc}
\hline Main criteria & Sub-criteria & Value (on a 10 point scale) \\
\hline II & Low & 1 to 3 \\
& Medium & 4 to 6 \\
UE & High & 7 to 10 \\
& Novice & 0,1 \\
& Manageable & 2,3 \\
& Adequate & 4,5 \\
& Skilled & 6 to 8 \\
AF & Expert & 9,10 \\
& Young & 1 to 3 \\
& Middle & 4 to 7 \\
\hline
\end{tabular}

Using the above assumptions, the criteria UE can be arrived as follows:

$$
\text { User experience }(\mathrm{UE})=(Y E \times 4)+\left(I D A \times \frac{20}{80}\right)
$$

Based on the value of UE, following crisp class assignment would be assigned to the second input variable UE:

$$
\text { User experience (UE) }=\left\{\begin{array}{cc}
\text { Manageable, } & 6<U E<20 \\
\text { Adequate, } & 21<U E<40 \\
\text { Skilled }, & 41<U E<60 \\
\text { Expert }, & 61<U E<100
\end{array}\right\}
$$

Similarly, for arriving at crisp value for the third variable AF, the following fuzzy classification is used:

$$
\text { Age }(\mathrm{AF})=\left\{\begin{array}{cc}
\text { Young, } & 17<\text { Age }<30 \\
\text { Middle, } & 31<\text { Age }<30 \\
\text { Old }, & 51<\text { age }<80
\end{array}\right\}
$$

Next in this process, the required inputs gathered from the designers using various subcriteria will be converted into crisp values. The process of mapping the obtained fuzzy values to crisp values can be done with Table 1 that was arrived based on our evidence based ranking as chosen in several studies as demonstrated in his contribution (Lindsay et al., 2012). The criterions were mapped to accommodate any classes of inputs so that the same can be chosen as a range instead of a single ordinal number. 


\section{Elucidating interaction styles and UI components}

In HCI, style of interaction determines the ease of use of any information systems as it directly relates the users' expectations and needs. Interaction style should strive for consistency, provide in advance the information, response with valid feedback, support reversal of actions, and try to prevent errors, cater diversity of users and minimise the short-term memory load. Simply, let the users take control of interaction process with the support of systems. In HCI literature, there were many forms of interaction styles suggested and the most widely accepted and familiar styles along with their advantages and disadvantages are described in Table 2.

Table 2 Nature of various interaction styles

\begin{tabular}{|c|c|c|}
\hline Interaction style & Advantages & Disadvantages \\
\hline $\begin{array}{l}\text { Direct } \\
\text { manipulation }\end{array}$ & $\begin{array}{l}\text { - Visually represents activity } \\
\text { concepts } \\
\text { - Minimises syntax } \\
\text { - Easy to learn } \\
\text { - Easy for retention } \\
\text { - Permit error avoidance } \\
\text { - Affords great individual } \\
\text { satisfaction }\end{array}$ & $\begin{array}{l}\text { - Perchance hard to program } \\
\text { - Involves graphical displays and } \\
\text { pointing/selecting devices }\end{array}$ \\
\hline Menu selection & $\begin{array}{l}\text { - Reduces learning } \\
\text { - Eases keystrokes } \\
\text { - Edifices DM } \\
\text { - Uses dialog-management tools } \\
\text { - Support error handling } \\
\text { - Guide through task }\end{array}$ & $\begin{array}{l}\text { - Provide danger of many menus } \\
\text { - Could slow down } \\
\text { frequent/expert users } \\
\text { - Guzzles screen space } \\
\text { - Involves rapid display rate }\end{array}$ \\
\hline Form fillin & $\begin{array}{l}\text { - Streamlines data entry } \\
\text { - Needs diffident training } \\
\text { - Contributes appropriate assistance }\end{array}$ & $\begin{array}{l}\text { - Chomps screen space } \\
\text { - May entail more competency }\end{array}$ \\
\hline $\begin{array}{l}\text { Command } \\
\text { language }\end{array}$ & $\begin{array}{l}\text { - Is bendable } \\
\text { - Demands to power/expert users } \\
\text { - Cares user's initiative } \\
\text { - Consents user-defined macros }\end{array}$ & $\begin{array}{l}\text { - Has reduced error handling } \\
\text { - Substantial preparation and } \\
\text { memorisation }\end{array}$ \\
\hline WIMP & $\begin{array}{l}\text { Combines the advantages of form-fill } \\
\text { in with menus }\end{array}$ & $\begin{array}{l}\text { Take time for users to get } \\
\text { familiarised }\end{array}$ \\
\hline Natural language & $\begin{array}{l}\text { - Dismisses problem of learning } \\
\text { syntax } \\
\text { - Enunciated NL allows busy } \\
\text { hands } \\
\text { - Can incorporate any modalities }\end{array}$ & $\begin{array}{l}\text { - Involves clarification dialog } \\
\text { - May need added keystrokes } \\
\text { - May not display environment } \\
\text { - Is random due to ambiguity } \\
\text { - Spoken harmed by noise }\end{array}$ \\
\hline
\end{tabular}




\subsection{UI elements}

While designing UI, try to make it consistent and predictable by designer's choice of UI elements. Whether users were aware of it or not, they would become familiar with interface elements behaving in a specified way, so selecting to approve those elements with proper controls would help with user for task completion, satisfaction and efficiency. Interface elements include controls for input like check boxes, buttons and navigational components like slider, search field, informational components like icons, tooltip and containers like accordion. Each interaction style may be associated with a particular set of UI elements so as to decide the final design of UI for any information system. Table 3 shows the various UI controls and elements with their uses and their alternatives along with the conditions to substitute them.

Table 3 UI elements with their alternatives

\begin{tabular}{|c|c|c|c|}
\hline Control type & Purpose & Alternate controls & $\begin{array}{l}\text { Conditions to use } \\
\text { alternate controls }\end{array}$ \\
\hline Check box & $\begin{array}{l}\text { To choose from } \\
\text { available options }\end{array}$ & Radio buttons & $\begin{array}{l}\text { Limited number of } \\
\text { options. }\end{array}$ \\
\hline Combo box & $\begin{array}{l}\text { To choose more than } \\
\text { one options from } \\
\text { available options. }\end{array}$ & $\begin{array}{l}\text { Drop-down list or list } \\
\text { box and a single-line } \\
\text { editable textbox. }\end{array}$ & $\begin{array}{l}\text { Number of options is } \\
\text { higher to be chosen } \\
\text { from the alternatives } \\
\text { editable help us to } \\
\text { narrow down the search }\end{array}$ \\
\hline $\begin{array}{l}\text { (Command) } \\
\text { button }\end{array}$ & $\begin{array}{l}\text { To choose any actions } \\
\text { in direct mode. }\end{array}$ & NONE & NA \\
\hline Dialogs & $\begin{array}{l}\text { Model and model less } \\
\text { dialogs which gives } \\
\text { information in parent } \\
\text { screen. }\end{array}$ & $\begin{array}{l}\text { Buttons and Grid } \\
\text { views of } \\
\text { icons/images. }\end{array}$ & $\begin{array}{l}\text { If number of icons or } \\
\text { images is limited in } \\
\text { numbers. }\end{array}$ \\
\hline Date picker & To choose date/time. & $\begin{array}{l}\text { Text box with } \\
\mathrm{dd} / \mathrm{mm} / \text { yyyy format. }\end{array}$ & $\begin{array}{l}\text { To minimise the } \\
\text { number of clicks to } \\
\text { search for a particular } \\
\text { date. }\end{array}$ \\
\hline Form & $\begin{array}{l}\text { To get inputs from the } \\
\text { users by combining } \\
\text { many input controls. }\end{array}$ & $\begin{array}{l}\text { Text boxes and list } \\
\text { boxes }\end{array}$ & $\begin{array}{l}\text { If inputs are limited and } \\
\text { require minimal } \\
\text { keystrokes and also } \\
\text { there should be less } \\
\text { number of available } \\
\text { choices to be } \\
\text { accommodated in list } \\
\text { boxes. }\end{array}$ \\
\hline $\begin{array}{l}\text { Groupbox } \\
\text { (Frame) }\end{array}$ & $\begin{array}{l}\text { To collect related set of } \\
\text { information }\end{array}$ & Grid based displays. & If the list is limited. \\
\hline Grids & $\begin{array}{l}\text { To collect related } \\
\text { information }\end{array}$ & Frames & $\begin{array}{l}\text { If there are limited } \\
\text { options and space. }\end{array}$ \\
\hline $\begin{array}{l}\text { Horizontal } \\
\text { scroll bar }\end{array}$ & $\begin{array}{l}\text { To view multiple } \\
\text { number of pages }\end{array}$ & $\begin{array}{l}\text { Use frames/new } \\
\text { hyperlinks. }\end{array}$ & $\begin{array}{l}\text { If we want to segregate } \\
\text { information into } \\
\text { groups. }\end{array}$ \\
\hline Image & To illustrate a concept & Icons & $\begin{array}{l}\text { If we want to reduce the } \\
\text { memory space. }\end{array}$ \\
\hline
\end{tabular}


Table 3 UI elements with their alternatives (continued)

\begin{tabular}{|c|c|c|c|}
\hline Control type & Purpose & Alternate controls & $\begin{array}{l}\text { Conditions to use } \\
\text { alternate controls }\end{array}$ \\
\hline Image combo & $\begin{array}{l}\text { Display a list of options } \\
\text { with images along } \\
\text { with. }\end{array}$ & $\begin{array}{l}\text { Use Icons/images with } \\
\text { a button. }\end{array}$ & $\begin{array}{l}\text { If there are limited } \\
\text { number of alternatives. }\end{array}$ \\
\hline Image list & Collection of images. & $\begin{array}{l}\text { Grid view if limited in } \\
\text { numbers. }\end{array}$ & $\begin{array}{l}\text { If the input image is } \\
\text { less in numbers and } \\
\text { also to enable users to } \\
\text { see available list } \\
\text { without any keystrokes } \\
\text { or clicks. }\end{array}$ \\
\hline Label & To name an item. & NONE & NA \\
\hline List box & $\begin{array}{l}\text { Displays list of options } \\
\text { to be chosen from. }\end{array}$ & $\begin{array}{l}\text { Check boxes/radio } \\
\text { buttons. }\end{array}$ & $\begin{array}{l}\text { If number of } \\
\text { alternatives is less. }\end{array}$ \\
\hline List view & $\begin{array}{l}\text { Displays a list of } \\
\text { scrollable items. }\end{array}$ & $\begin{array}{l}\text { Frames and } \\
\text { hyperlinks. }\end{array}$ & $\begin{array}{l}\text { Use in case of more } \\
\text { items to be displayed. }\end{array}$ \\
\hline Menu & $\begin{array}{l}\text { Collection of user } \\
\text { actions. }\end{array}$ & $\begin{array}{l}\text { Command line } \\
\text { interface. } \\
\text { Radio buttons. } \\
\text { Buttons with images } \\
\text { representing actions. }\end{array}$ & $\begin{array}{l}\text { Familiarity of the users } \\
\text { with adequate } \\
\text { knowledge about input } \\
\text { devices and commands. } \\
\text { Limited choices. } \\
\text { Frequently triggered } \\
\text { actions. } \\
\text { To save space. }\end{array}$ \\
\hline Month view & $\begin{array}{l}\text { To display the calendar } \\
\text { month wise. }\end{array}$ & NONE & NA \\
\hline Tab control & $\begin{array}{l}\text { By using a tab control, } \\
\text { an application can } \\
\text { define multiple pages } \\
\text { for the same area of a } \\
\text { window or dialog box. }\end{array}$ & Frames/Grid layouts & $\begin{array}{l}\text { If the information } \\
\text { occupies more space. }\end{array}$ \\
\hline Picture box & To display images & NONE & NA \\
\hline Progress bar & $\begin{array}{l}\text { To denote the status of } \\
\text { completion of a task. }\end{array}$ & Simple dialog. & To reduce space. \\
\hline $\begin{array}{l}\text { Radio Button } \\
\text { (Option button) }\end{array}$ & $\begin{array}{l}\text { To choose one option } \\
\text { from the existing set. }\end{array}$ & Combo box & $\begin{array}{l}\text { Under any } \\
\text { circumstances. }\end{array}$ \\
\hline Rich text box & $\begin{array}{l}\text { To display or edit rich } \\
\text { content including } \\
\text { paragraphs, hyperlinks, } \\
\text { and inline images. }\end{array}$ & Editable text area & $\begin{array}{l}\text { Can be altered without } \\
\text { any constraints. }\end{array}$ \\
\hline Slider & $\begin{array}{l}\text { Used for a slideshow } \\
\text { added into a web page. }\end{array}$ & Grid view of slides & Reduce loading time \\
\hline
\end{tabular}


Table 3 UI elements with their alternatives (continued)

\begin{tabular}{|c|c|c|c|}
\hline Control type & Purpose & Alternate controls & $\begin{array}{l}\text { Conditions to use } \\
\text { alternate controls }\end{array}$ \\
\hline Status bar & $\begin{array}{l}\text { Poses an information } \\
\text { area typically found at } \\
\text { the window's bottom. } \\
\text { It can be divided into } \\
\text { sections to group } \\
\text { information. }\end{array}$ & $\begin{array}{l}\text { Can be displayed in a } \\
\text { simple popup dialog to } \\
\text { reduce space. }\end{array}$ & NA \\
\hline Text box & To read inputs. & $\begin{array}{l}\text { Check box/radio } \\
\text { buttons/list Editable } \\
\text { text box to facilitate } \\
\text { users search. } \\
\text { Natural language. }\end{array}$ & $\begin{array}{l}\text { If limited and known } \\
\text { number of inputs. } \\
\text { If input contains more } \\
\text { keystrokes. }\end{array}$ \\
\hline Timer & $\begin{array}{l}\text { Execute certain } \\
\text { functionalities in a } \\
\text { regular interval. }\end{array}$ & $\begin{array}{l}\text { Can use functions in } \\
\text { scripting with time } \\
\text { intervals. }\end{array}$ & $\begin{array}{l}\text { To minimise the } \\
\text { chances of hardware } \\
\text { failure. }\end{array}$ \\
\hline Toolbar & $\begin{array}{l}\text { One among the web } \\
\text { page control options } \\
\text { that displays available } \\
\text { list of tools. }\end{array}$ & NONE & NA \\
\hline Tree view & $\begin{array}{l}\text { Displays hierarchical } \\
\text { data, such as a table of } \\
\text { contents, in a tree } \\
\text { structure. }\end{array}$ & $\begin{array}{l}\text { Can use on-demand } \\
\text { dialogs with tool tip. }\end{array}$ & $\begin{array}{l}\text { To reduce the space } \\
\text { occupied in a page. }\end{array}$ \\
\hline Up Down & $\begin{array}{l}\text { It is made up of one } \\
\text { textbox and two } \\
\text { buttons to increment or } \\
\text { decrement the value. }\end{array}$ & $\begin{array}{l}\text { Text box if input size } \\
\text { is small. }\end{array}$ & $\begin{array}{l}\text { Instead of clicking } \\
\text { many times for } \\
\text { changing a value, text } \\
\text { box can be used. }\end{array}$ \\
\hline $\begin{array}{l}\text { Vertical scroll } \\
\text { bar }\end{array}$ & $\begin{array}{l}\text { Enables the user to } \\
\text { scroll the content up or } \\
\text { down. }\end{array}$ & Frames/Grids & $\begin{array}{l}\text { Can use to minimise } \\
\text { users time for scrolling. }\end{array}$ \\
\hline
\end{tabular}

Selecting proper controls depends on various factors. The vital one is the structure and physiognomies of the data. Others include the nature of the job, the user's nature, and the boundaries of the display unit itself. Few controls are very limiting by nature that they would permit only definite types of information with definite qualities to be accessible within them. Other controls were not as preventive concerning quality of data, but they were not suited well for the kind of data to be used.

\subsection{UI elements for interaction styles with input devices}

Not all the UI elements would fit for any kinds of interaction styles. Based on the users, context and application, they vary from system to system. From the literature of UI 
design and HCI, Table 4 maps the corresponding UI elements for various interaction styles. The table was constructed using various ISO standards in HCI including ISO 9241 for Standard for Ergonomics requirements and dialog design, ISO/IEC 10741-1 for dialog interactions like cursor control and editing text, ISO/IEC 11581 for icons and functions and ISO 9126 for software quality and characteristics.

Table 4 User interaction with input devices and UI elements

\begin{tabular}{|c|c|c|c|}
\hline Interaction Styles & Devices & Controls & Actions \\
\hline $\begin{array}{l}\text { Direct } \\
\text { manipulation }\end{array}$ & $\begin{array}{c}\text { Mouse } \\
\text { Stylus } \\
\text { Track ball } \\
\text { Touch screen }\end{array}$ & $\begin{array}{c}\text { Icons } \\
\text { Widgets }\end{array}$ & $\begin{array}{l}\text { Drag and drop } \\
\text { Click }\end{array}$ \\
\hline Menu & $\begin{array}{c}\text { Mouse } \\
\text { Light pen } \\
\text { Touch screen } \\
\text { Keyboard }\end{array}$ & $\begin{array}{c}\text { Text box } \\
\text { List box } \\
\text { Combo box } \\
\text { Icons } \\
\text { Widgets } \\
\text { Commands } \\
\text { Short cut keys }\end{array}$ & $\begin{array}{l}\text { Type or click to } \\
\text { choose. } \\
\text { Short cut keys to } \\
\text { activate items. } \\
\text { Selection of one } \\
\text { or more items. }\end{array}$ \\
\hline Forms & $\begin{array}{l}\text { Keyboard } \\
\text { Mouse } \\
\text { Touch screen } \\
\text { Code readers } \\
\text { Scanners } \\
\text { Mike }\end{array}$ & $\begin{array}{c}\text { Text Box } \\
\text { Radio button } \\
\text { File select } \\
\text { Button } \\
\text { Text area } \\
\text { List Box } \\
\text { Voice Recognisers }\end{array}$ & $\begin{array}{l}\text { Choose or type. } \\
\text { Select files. } \\
\text { Submit data. }\end{array}$ \\
\hline CLI & $\begin{array}{c}\text { Keyboard } \\
\text { Touch screen } \\
\text { Mike }\end{array}$ & $\begin{array}{c}\text { Text box } \\
\text { Text area } \\
\text { Graphics } \\
\text { Voice recognisers }\end{array}$ & $\begin{array}{l}\text { Interact with } \\
\text { commands } \\
\text { mostly through } \\
\text { keying in them. }\end{array}$ \\
\hline WIMP & $\begin{array}{l}\text { Keyboard } \\
\text { Mouse } \\
\text { Scanner } \\
\text { Code readers } \\
\text { Scanners } \\
\text { Joy stick } \\
\text { Bio metric } \\
\text { devices } \\
\text { Mike }\end{array}$ & $\begin{array}{c}\text { Text box } \\
\text { Text area } \\
\text { Recognisers } \\
\text { Synthesisers } \\
\text { Buttons } \\
\text { List box } \\
\text { Combo box } \\
\text { Date pickers }\end{array}$ & $\begin{array}{l}\text { Combination of } \\
\text { multiple } \\
\text { components to } \\
\text { facilitate } \\
\text { interaction easier. }\end{array}$ \\
\hline Natural & $\begin{array}{l}\text { Bio metric } \\
\text { devices } \\
\text { Code readers } \\
\text { Sensors } \\
\text { Speakers } \\
\text { Web cam } \\
\text { Mike }\end{array}$ & $\begin{array}{c}\text { Recognisers } \\
\text { Synthesisers } \\
\text { Text analysers } \\
\text { Audio/video processors } \\
\text { Widgets }\end{array}$ & $\begin{array}{l}\text { Speak and act to } \\
\text { interact. }\end{array}$ \\
\hline
\end{tabular}

By analysing the table, any designer could conclude the interaction styles for any category of users with their interaction devices and UI elements so as to make interaction easier. Many UI elements may also be replaced with alternatives in case if needed depending on the feasibility and context. 


\section{TOPSIS for UI design}

As suggested, this method uses three inputs from the user to recommend the designer with UI design namely II, UE and AF. Based on the values and procedure discussed above, they are mapped into one of the fuzzy classes. Use Table 1 for mapping these fuzzy values into crisp values and TOPSIS method will be applied. A simple illustration is given below:

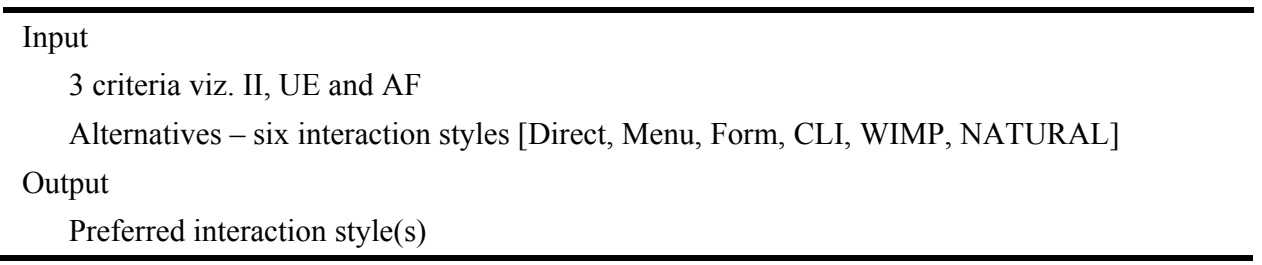

Assume the following criteria are chosen to illustrate use of TOPSIS for this recommendation:

- $\quad$ II - low

- UE - manageable

- $\mathrm{AF}-$ young.

Studying the performance of information systems (DeLone and Mclean, 1992), it was identified that the usability depends on the given criteria in any information system's performance measurement in varied proportion with respect to the context and applications. In this recommendation, the student academics portal was considered to ideally apply the proposed technique. So, the three usability criteria take the proportion of $30 \%, 40 \%$ and $30 \%$ viz., II, UE and AF. Normalising the same would yield II: 0.3 , $\mathrm{UE}-0.4, \mathrm{AF}-0.3$ [Sum of the weightage is 1].

The following procedure illustrates TOPSIS to rank alternatives using the chosen three criteria.

Initial decision matrix based on the mentioned TOPSIS procedures for various input criteria along with their weights mentioned against their name is given in Table 5.

Table 5 Initial decision matrix

\begin{tabular}{lccc}
\hline Alternative vs. criteria & $I I(0.3)$ & $U E(0.4)$ & $A F(0.3)$ \\
\hline DIRECT & 3 & 2 & 1 \\
MENU & 1 & 3 & 3 \\
FORM & 1 & 2 & 1 \\
CLI & 1 & 2 & 1 \\
WIMP & 1 & 2 & 3 \\
NATURAL & 3 & 3 & 1 \\
\hline
\end{tabular}


Step 1 Construction of normalised decision matrix using the equation (1). Table 6 shows the result of Step 1.

Table 6 Normalised decision matrix

\begin{tabular}{lccc}
\hline Alternative vs. criteria & $I I$ & $U E$ & $A F$ \\
\hline DIRECT & 0.1364 & 0.0588 & 0.0455 \\
MENU & 0.0455 & 0.0882 & 0.1364 \\
FORM & 0.0455 & 0.0588 & 0.0455 \\
CLI & 0.0455 & 0.0588 & 0.0455 \\
WIMP & 0.0455 & 0.0588 & 0.1364 \\
NATURAL & 0.1364 & 0.0882 & 0.0455 \\
\hline
\end{tabular}

Step 2 Construction of weighted decision matrix by applying equation (2). Table 7 shows the result of Step 2.

Table 7 Weighted decision matrix

\begin{tabular}{lccc}
\hline Alternative vs. criteria & $I I$ & $U E$ & $A F$ \\
\hline DIRECT & 0.0409 & 0.0235 & 0.0136 \\
MENU & 0.0136 & 0.0353 & 0.0409 \\
FORM & 0.0136 & 0.0235 & 0.0136 \\
CLI & 0.0136 & 0.0235 & 0.0136 \\
WIMP & 0.0136 & 0.0235 & 0.0409 \\
NATURAL & 0.0409 & 0.0353 & 0.0136 \\
\hline
\end{tabular}

Step 3 Find PIS and NIS using equations (3)-(6). The result obtained is given in Tables 8 and 9 .

Table 8 Calculated PIS and NIS

\begin{tabular}{lccc}
\hline Solution vs. criteria & II & $U E$ & $A F$ \\
\hline PIS & 0.0409 & 0.0353 & 0.0409 \\
NIS & 0.0136 & 0.0235 & 0.0136 \\
\hline
\end{tabular}

Step 4 Calculate separation measures using equation (7) for PIS and equation (8) for NIS. Result is given in Table 9 for PIS and Table 10 gives the same for NIS.

Table 9 PIS separation measure

\begin{tabular}{lccc}
\hline Alternative vs. criteria & $I I$ & $U E$ & $A F$ \\
\hline DIRECT & 0 & 0.0001 & 0.0007 \\
MENU & 0.0007 & 0 & 0 \\
FORM & 0.0007 & 0.0001 & 0.0007 \\
CLI & 0.0007 & 0.0001 & 0.0007 \\
WIMP & 0.0007 & 0.0001 & 0 \\
NATURAL & 0 & 0 & 0.0007 \\
\hline
\end{tabular}


Table 10 NIS separation measure

\begin{tabular}{lccc}
\hline Alternative vs. criteria & $I I$ & $U E$ & $A F$ \\
\hline DIRECT & 0.0007 & 0 & 0 \\
MENU & 0 & 0.0001 & 0.0007 \\
FORM & 0 & 0 & 0 \\
CLI & 0 & 0 & 0 \\
WIMP & 0 & 0 & 0.0007 \\
NATURAL & 0.0007 & 0.0001 & 0 \\
\hline
\end{tabular}

Step 5 Find the relative closeness to PIS by applying equation (9). Result is given in the Table 11.

Table 11 Relative closeness of alternatives

\begin{tabular}{lcc}
\hline Alternatives & Closeness & Rank \\
\hline DIRECT & 0.4574 & 2 \\
MENU & 0.5426 & 1 \\
FORM & 0 & NA \\
CLI & 0 & NA \\
WIMP & 0.4574 & 2 \\
NATURAL & 0.5426 & 1 \\
\hline
\end{tabular}

The next step would be to identify the UI design elements which can be done with oneon-one mapping with the Table 4 . So, for the above category of user, the interface would be designed using text box, list box, combo box, icons, widgets, short cut keys, buttons and text area.

From the final relative closeness of the PIS in the table, it is observed that any user between 17-30, who can manage as an individual under any dynamic environment with their own previous experience can be recommended with the MENU based or NATURAL language based interaction styles. Also, for these kinds of users, interaction styles like FORM fill-in and command line interface (CLI) would not be used to model their interaction.

Similarly, for the remaining categories of inputs, following results shown in Table 12 were obtained using TOPSIS method.

Table 12 Suitable interaction styles for various input criteria

\begin{tabular}{lccc}
\hline Interaction style & $I I$ & $U E$ & $A F$ \\
\hline DIRECT & LOW & NOVICE & YOUNG \\
& & NOVICE & OLD \\
& & SKILLED & OLD \\
& & EXPERT & OLD \\
\multirow{2}{*}{ MEDIUM } & NOVICE & YOUNG \\
& & MANAGEABLE & YOUNG \\
& EXPERT & OLD \\
& HIGH & SKILLED & MIDDLE \\
& & SKILLED & OLD \\
\hline
\end{tabular}


Table 12 Suitable interaction styles for various input criteria (continued)

\begin{tabular}{|c|c|c|c|}
\hline Interaction style & $I I$ & $U E$ & $A F$ \\
\hline \multirow[t]{13}{*}{ MENU } & LOW & MANAGEABLE & YOUNG \\
\hline & & SKILLED & YOUNG \\
\hline & MEDIUM & NOVICE & MIDDLE \\
\hline & & NOVICE & OLD \\
\hline & & MANAGEABLE & OLD \\
\hline & & ADEQUATE & YOUNG \\
\hline & & ADEQUATE & MIDDLE \\
\hline & & SKILLED & YOUNG \\
\hline & & EXPERT & YOUNG \\
\hline & HIGH & NOVICE & YOUNG \\
\hline & & NOVICE & OLD \\
\hline & & EXPERT & YOUNG \\
\hline & & EXPERT & OLD \\
\hline \multirow[t]{9}{*}{ FORM } & LOW & MANAGEABLE & MIDDLE \\
\hline & & ADEQUATE & YOUNG \\
\hline & & SKILLED & MIDDLE \\
\hline & & EXPERT & YOUNG \\
\hline & MEDIUM & MANAGEABLE & MIDDLE \\
\hline & HIGH & NOVICE & MIDDLE \\
\hline & & MANAGEABLE & MIDDLE \\
\hline & & MANAGEABLE & OLD \\
\hline & & ADEQUATE & MIDDLE \\
\hline FORM & HIGH & EXPERT & MIDDLE \\
\hline \multirow[t]{3}{*}{ CLI } & MEDIUM & SKILLED & OLD \\
\hline & & EXPERT & MIDDLE \\
\hline & HIGH & SKILLED & YOUNG \\
\hline \multirow[t]{7}{*}{ WIMP } & LOW & MANAGEABLE & OLD \\
\hline & & ADEQUATE & MIDDLE \\
\hline & & EXPERT & MIDDLE \\
\hline & MEDIUM & ADEQUATE & OLD \\
\hline & & SKILLED & MIDDLE \\
\hline & HIGH & MANAGEABLE & YOUNG \\
\hline & & ADEQUATE & YOUNG \\
\hline \multirow[t]{3}{*}{ NATURAL } & LOW & NOVICE & MIDDLE \\
\hline & & ADEQUATE & OLD \\
\hline & HIGH & ADEQUATE & OLD \\
\hline
\end{tabular}


Thus, for any category of users with various levels of experience having any depth of interactions, the interaction styles were arrived with the help of TOPSIS method. Then, choosing the corresponding UI elements using one-on-one basis is performed using the Table 4. The implementation of the recommendation depends on the economic feasibility. Sometimes, additional requirements may involve huge investment.

\section{Evaluation of our proposed methodology}

The recommendations arrived by using TOPSIS method in this work were purely based on evidence-based reasoning. The conclusions arrived can be evaluated using Dempster-Shafer theory (DST) or evidence theory to prove the trueness of the rules framed by means of a certainty factor. Certainty factor is a measure used to assess the goodness of belief and disbelief around a framed rule. Thus, this reasoning relies on degree of belief and disbelief to prove their correctness based on the expert's opinion and evidences followed.

Consider the following conclusion (belief) arrived at by applying TOPSIS.

If intensity interaction is MEDIUM and UE is SKILLED and AF is YOUNG then interactions style is MENU.

The certainty factor associated with conclusion of the rule $\mathrm{CF}(\mathrm{R})$ is considered to be 0.8 . Hence, according to the expert, the liability of consequence due to antecedents is more. Further, facts around the independent variables in antecedents intensity interaction, $\mathrm{UE}$ and $\mathrm{AF}$ has been initialised with the values $0.6,0.8$ and 0.6 based on the empirical study. Thus, the proof for the certainty factor assigned is evaluated as follows:

Certainty factors for rules associated with more than one evidences is calculated as follows:

$$
\begin{aligned}
& \mathrm{CF}(\mathrm{E})=(\mathrm{CF}(\mathrm{e} 1), \mathrm{CF}(\mathrm{e} 2), \ldots, \mathrm{CF}(\mathrm{en})) \\
& \mathrm{CF}(\mathrm{E})=\min [\mathrm{CF}(\mathrm{e} 1), \mathrm{CF}(\mathrm{e} 2), \ldots, \mathrm{CF}(\mathrm{en})]
\end{aligned}
$$

So, here in the chosen case:

$$
\mathrm{CF}(\text { Evidences })=\min [0.6,0.8,0.6]
$$

$$
\begin{aligned}
& \mathrm{CF}(\mathrm{E})=0.6 \\
& \mathrm{CF}(\mathrm{E}, \text { Rule })=\mathrm{CF}(\mathrm{E}) \times \mathrm{CF}(\text { Rule }) \\
& \mathrm{CF}=0.8 \times 0.6=0.48
\end{aligned}
$$

The calculated CF value leads to the fact that the rule is valid.

Consider a similar rule:

If intensity interaction is MEDIUM and UE is SKILLED and AF is YOUNG then interactions style is DIRECT.

From the conclusions arrived, it would be highly impossible for the same rule to have different conclusion and so the disbelief factor associated with the rule dominate here. 
Let the CF value for the rule is 0.2 (As we know that the rule has only one conclusion. In the previous case, it was given value 0.8 ).

Now,

$$
\begin{aligned}
& \mathrm{CF}(\text { Evidences })=\min [0.6,0.8,0.6] \\
& \mathrm{CF}(\mathrm{E})=0.6 \\
& \mathrm{CF}(\mathrm{E}, \text { Rule })=\mathrm{CF}(\mathrm{E}) \times \mathrm{CF}(\text { Rule }) \\
& \mathrm{CF}=0.2 \times 0.6=0.12
\end{aligned}
$$

The result obtained indicates that the conclusion arrived with the above independent variables may be ignored as the resulting possibility of accepting the same conclusion is more deviated from the belief factor 1 when compared to the previous conclusion. So, based on the degree of deviations from assigned measure of belief (MB) and measure of disbelief (MD), any conclusions associated with certainty factors is accepted or eliminated from the observed conclusions. Thus, all the conclusions associated with MB and MD values together with the independent values can be proved that the conclusions arrived are acceptable.

\section{Conclusions}

The system is proposed to recommend the preferred style of interaction for any categories of user in a dynamic context. A multi-criterion decision analysis is performed for determining the appropriate user interaction style. The analysis included II, UE and AF of users to establish connectivity across these factors and an appropriate interaction style that is convenient for the users. The decision process is envisioned through TOPSIS method of analysis where the appropriate combinations of inputs are ranked and firm rules are established for reasoning. Further, evidence-based reasoning is performed to affirm the generated rules for deciding the interaction style. The study revealed the possibilities of various recommendations towards deciding the UI through proper interaction styles and controls which could be followed for an effective UI design. The system designed may further be extended with vibrant inclusion of fuzzy inferences and optimisations which may be quite helpful for sentimental analysis and behaviour analysis of users.

\section{References}

Bihler, P. and Mügge, H. (2007) 'Supporting cross-application contexts with dynamic user interface fusion', in GI Jahrestagung, Vol. 1, No. 1, pp.459-464.

Blumendorf, M., Feuerstack, S. and Albayrak, S. (2007) 'Multimodal user interaction in smart environments: delivering distributed user interfaces', in European Conference on Ambient Intelligenc., pp.113-120.

Boran, F.E., Genç, S., Kurt, M. and Akay, D. (2009) 'A multi-criteria intuitionistic fuzzy group decision making for supplier selection with TOPSIS method', Expert Systems with Applications, Vol. 36, No. 8, pp.11363-11368.

Byrne, E.A. and Parasuraman, R. (1996) 'Psychophysiology and adaptive automation', Biological Psychology, Vol. 42, No. 3, pp.249-268. 
Calvary, G. and Coutaz, J. (2014) Introduction to Model-Based User Interfaces, W3C Group Note NOTE-Mbui-Intro-20140107.

Calvary, G., Coutaz, J., Thevenin, D., Limbourg, Q., Bouillon, L. and Vanderdonckt, J. (2003) 'A unifying reference framework for multi-target user interfaces', Interacting with Computers, Vol. 15, No. 3, pp.289-308.

Chen, C-T. (2000) 'Extensions of the TOPSIS for group decision-making under fuzzy environment', Fuzzy Sets and Systems, Vol. 114, No. 1, pp.1-9.

Chen, W. and Shih, C-C. (2012) 'Architecture of portable electronic medical records system integrated with streaming media', Journal of Medical Systems, Vol. 36, No. 1, pp.25-31, DOI: $10.1007 / \mathrm{s} 10916-010-9442-\mathrm{y}$.

Coutaz, J. (2010) 'User interface plasticity: model driven engineering to the limit!', in Proceedings of the 2nd ACM SIGCHI Symposium on Engineering Interactive Computing Systems, pp.1-8.

Delone, W. and Mclean, E. (1992) 'Information systems success: the quest for the dependent variable', Information Systems Research, Vol. 3, No. 1, pp.60-95.

Demeure, A., Calvary, G. and Coninx, K. (2008) 'COMET(s), a software architecture style and an interactors toolkit for plastic user interfaces' in International Workshop on Design, Specification, and Verification of Interactive Systems, pp.225-237.

Dymova, L., Sevastjanov, P. and Tikhonenko, A. (2013) 'A direct interval extension of TOPSIS method', Expert Systems with Applications, Vol. 40, No. 12, pp.4841-4847.

Espinilla, M., de Andrés, R., Martínez, F.J. and Martínez, L. (2013) 'A 360-degree performance appraisal model dealing with heterogeneous information and dependent criteria', Information Sciences, Vol. 222, No. 1, pp.459-471.

Gajos, K.Z., Weld, D.S. and Wobbrock, J.O. (2010) 'Automatically generating personalized user interfaces with Supple’, Artificial Intelligence, Vol. 174, No. 12, pp.910-950.

Jahanshahloo, G.R., Lotfi, F.H. and Davoodi, A.R. (2009) 'Extension of TOPSIS for decision-making problems with interval data: Interval efficiency', Mathematical and Computer Modelling, Vol. 49, No. 5, pp.1137-1142.

Keates, S., Clarkson, P.J., Harrison, L-A. and Robinson, P. (2000) 'Towards a practical inclusive design approach', in Proceedings on the 2000 Conference on Universal Usability, pp.45-52.

Krohling, R.A. and Campanharo, V.C. (2011) 'Fuzzy TOPSIS for group decision making: a case study for accidents with oil spill in the sea', Expert Systems with Applications, Vol. 38, No. 4, pp.4190-4197.

Lee, G., Jun, K.S. and Chung, E-S. (2014) 'Robust spatial flood vulnerability assessment for Han River using fuzzy TOPSIS with $\alpha$-cut level set', Expert Systems with Applications, Vol. 41, No. 2, pp.644-654.

Lindsay, S., Jackson, D., Schofield, G. and Olivier, P. (2012) 'Engaging older people using participatory design', in Proceedings of the SIGCHI Conference on Human Factors in Computing Systems, pp.1199-1208.

Lourenzutti, R. and Krohling, R.A. (2014) 'The Hellinger distance in multicriteria decision making: an illustration to the TOPSIS and TODIM methods', Expert Systems with Applications, Vol. 41, No. 9, pp.4414-4421.

Mace, R.L., Hardie, G.J. and Place, J.P. (1990) Accessible Environments: Toward Universal Design, Center for Accessible Housing, North Carolina State University.

Nielsen, J. (1986) 'A virtual protocol model for computer-human interaction', International Journal of Man-Machine Studies, Vol. 24, No. 3, pp.301-312.

Pederiva, I., Vanderdonckt, J., España, S., Panach, I. and Pastor, O. (2007) 'The beautification process in model-driven engineering of user interfaces', in IFIP Conference on Human-Computer Interaction, pp.411-425.

Peng, D.H., Gao, C.Y. and Wu, L.X. (2012) 'TOPSIS-based multi-criteria group decision making under heterogeneous information setting', in Advanced Materials Research, Vol. 378, No. 1, pp.525-530. 
Pérez, I.J., Cabrerizo, F.J. and Herrera-Viedma, E. (2010) 'A mobile decision support system for dynamic group decision-making problems', IEEE Transactions on Systems, Man, and Cybernetics-Part A: Systems and Humans, Vol. 40, No. 6, pp.1244-1256.

Pérez, I.J., Cabrerizo, F.J. and Herrera-Viedma, E. (2011) 'Group decision making problems in a linguistic and dynamic context', Expert Systems with Applications, Vol. 38, No. 3, pp.1675-1688.

Reinecke, K. and Bernstein, A. (2011) 'Improving performance, perceived usability, and aesthetics with culturally adaptive user interfaces', ACM Transactions on Computer-Human Interaction (TOCHI), Vol. 18, No. 2, p.8.

Rogers, Y., Paay, J., Brereton, M., Vaisutis, K.L., Marsden, G. and Vetere, F. (2014) 'Never too old: engaging retired people inventing the future with MaKey MaKey', in Proceedings of the SIGCHI Conference on Human Factors in Computing Systems, pp.3913-3922.

Run-qi, W. et al. (2008) 'Hybrid random multi-criteria decision-making approach with incomplete certain information', in 2008 Chinese Control and Decision Conference, pp.1444-1448.

Sangiorgi, D. and Prendiville, A. (2014) 'A theoretical framework for studying service design practices: first steps to a mature field', Design Management Journal, Vol. 9, No. 1, pp.61-73.

Shen, J. and Pantic, M. (2013) ' $\mathrm{HCI}^{2}$ framework: a software framework for multimodal human-computer interaction systems', IEEE Transactions on Cybernetics, Vol. 43, No. 6, pp.1593-1606, DOI: 10.1109/TCYB.2013.2271563.

Shih, H-S., Shyur, H-J. and Lee, E.S. (2007) 'An extension of TOPSIS for group decision making', Mathematical and Computer Modelling, Vol. 45, No. 7, pp.801-813.

Singh, A. and Wesson, J. (2009) 'Evaluation criteria for assessing the usability of ERP systems', in Proceedings of the 2009 Annual Research Conference of the South African Institute of Computer Scientists and Information Technologists, pp.87-95.

Solovey, E.T., Lalooses, F., Chauncey, K., Weaver, D., Parasi, M., Scheutz, M. et al. (2011) 'Sensing cognitive multitasking for a brain-based adaptive user interface', in Proceedings of the SIGCHI Conference on Human Factors in Computing Systems, pp.383-392.

Stephanidis, C. (1997) 'Towards the next generation of UIST: developing for all users', Proceedings of the Seventh International Conference on Human-Computer Interaction, 24-29 August, Vol. 1, pp.473-476, New York, USA.

Sun, Y., Ding, X., Lindtner, S., Lu, T. and Gu, N. (2014) 'Being senior and ICT: a study of seniors using ICT in China', in Proceedings of the SIGCHI Conference on Human Factors in Computing Systems, pp.3933-3942.

Topi, H., Lucas, W.T. and Babaian, T. (2005) 'Identifying usability issues with an ERP implementation', in ICEIS, pp.128-133.

Ureña, R., Chiclana, F., Morente-Molinera, J.A. and Herrera-Viedma, E. (2015) 'Managing incomplete preference relations in decision making: a review and future trends', Information Sciences, Vol. 302, No. 1, pp.14-32.

Vahdani, B., Mousavi, S.M. and Tavakkoli-Moghaddam, R. (2011) 'Group decision making based on novel fuzzy modified TOPSIS method', Applied Mathematical Modelling, Vol. 35, No. 9, pp.4257-4269.

Vanderdonckt, J. (1997) Conception Assist\{é\}e de la Pr\{é\}sentation d'une Interface Homme-machine Ergonomique Pour une Application de Gestion Hautement Interactive, Universit $\{$ é\} Libre de Bruxelles, Institut d'Informatique Namur.

Wan, S-P. and Li, D-F. (2013) 'Fuzzy LINMAP approach to heterogeneous MADM considering comparisons of alternatives with hesitation degrees', Omega, Vol. 41, No. 6, pp.925-940.

Xiong, W. and Qi, H. (2010) 'A extended TOPSIS method for the stochastic multi-criteria decision making problem through interval estimation', in Intelligent Systems and Applications (ISA), 2nd International Workshop on, pp.1-4. 
Xu, Z. and Zhang, X. (2013) 'Hesitant fuzzy multi-attribute decision making based on TOPSIS with incomplete weight information', Knowledge-Based Systems, Vol. 52, No. 1, pp.53-64.

Yoon, K.P. and Hwang, C.L., (1995) 'Multiple attribute decision making: an introduction', Sage Publications. Vol. 104, No. 1, pp.38-45.

Yue, Z. (2011) 'An extended TOPSIS for determining weights of decision makers with interval numbers', Knowledge-Based Systems, Vol. 24, No. 1, pp.146-153. 